\title{
LC-ESI/LTQOrbitrap/MS Metabolomic Analysis of Fennel Waste (Foeniculum vulgare Mill.) as a Byproduct Rich in Bioactive Compounds
}

\author{
Maria Assunta Crescenzi, Gilda D’Urso (D), Sonia Piacente and Paola Montoro *(D) \\ Dipartimento di Farmacia, Università Degli Studi di Salerno, via Giovanni Paolo II n. 132, \\ I-84084 Fisciano, SA, Italy; mcrescenzi@unisa.it (M.A.C.); gidurso@unisa.it (G.D.); piacente@unisa.it (S.P.) \\ * Correspondence: pmontoro@unisa.it
}

\section{check for} updates

Citation: Crescenzi, M.A.; D’Urso, G.; Piacente, S.; Montoro, P. LC-ESI/LTQOrbitrap/MS Metabolomic Analysis of Fennel Waste (Foeniculum vulgare Mill.) as a Byproduct Rich in Bioactive Compounds. Foods 2021, 10, 1893. https://doi.org/10.3390/ foods10081893

Academic Editor: Flaminia

Cesare Marincola

Received: 21 July 2021

Accepted: 13 August 2021

Published: 15 August 2021

Publisher's Note: MDPI stays neutral with regard to jurisdictional claims in published maps and institutional affiliations.

Copyright: (c) 2021 by the authors. Licensee MDPI, Basel, Switzerland. This article is an open access article distributed under the terms and conditions of the Creative Commons Attribution (CC BY) license (https:// creativecommons.org/licenses/by/ $4.0 /)$.

\begin{abstract}
Food industries produce a high amount of waste every year. These wastes represent a source of bioactive compounds to be used to produce cosmetic and nutraceutical products. In this study, the possibility to retrain food waste as a potential source of bioactive metabolites is evaluated. In particular, metabolite profiles of different parts (bulb, leaves, stems and little stems) of fennel waste were investigated by liquid chromatography coupled with mass spectrometry (LC-ESI/LTQ Orbitrap MS). To discriminate the different plant parts, a Multivariate Data Analysis approach was developed. Metabolomic analysis allowed the identification of different metabolites mainly belonging to hydroxycinnamic acid derivatives, flavonoid glycosides, flavonoid aglycons, phenolic acids, iridoid derivatives and lignans. The identification of compounds was based on retention times, accurate mass measurements, MS/MS data, exploration on specific metabolites database and comparison with data reported in the literature for F. vulgare. Moreover, the presence of different oxylipins was relieved; these metabolites for the first time were identified in fennel. Most of the metabolites identified in F. vulgare possess anti-inflammatory, antioxidant and/or immunomodulatory properties. Considering that polyphenols are described to possess antioxidant activity, spectrophotometric tests were performed to evaluate the antioxidant activity of each part of the fennel.
\end{abstract}

Keywords: waste; bioactive compounds; nutraceutical products; mass spectrometry; metabolomic; biological properties

\section{Introduction}

Foeniculum vulgare (Apiaceae/Umbellifearae), also known as fennel, is a perennial aromatic plant, originally from Asia Minor and Mediterranean regions [1]. At present, it is widespread to all temperate zones, prefers arid ground and does not tolerate cold or humid climates. Fennel presents straight stems with an intense green-blue color that can grow to heights of up to $2.5 \mathrm{~m}$. The stems are finely divided into leaves composed of many filiform segments. The sheath leaves form the white bulb wrapping around the stems at the base. The flowers are a terminal part of the plant, yellow umbels $5-15 \mathrm{~cm}$ wide. Aromatic and carminative fruits reach a length of 4-10 $\mathrm{mm}$ and are surrounded by dried seeds [1-3].

In the last years, vegetable waste has received a lot of attention as an ingredient intended to produce cosmetics and nutraceuticals [4-7]. The waste of F. vulgare is a good source of polyphenols thus making it a great by-product with anti-inflammatory, antioxidant, immunomodulatory and apoptotic properties [8-10]. Several species belonging to Umbelliferae have been shown to influence immunity, playing a central role in a variety of diseases [11-13]. Thus, a diet rich in polyphenol compounds like flavonoids (such as quercetin and rutin) and coumarins can help to prevent diseases such as cancer, cardiovascular and neurodegenerative pathologies [14-16]. The bioactivity of polyphenols such as chlorogenic acid, ferulic acid and caffeic acid, is correlated with the increase in the activity 
of human lymphocyte proliferation and high-level production of INF- $\gamma$, enhancing the efficacy of host defense against intracellular pathogenesis and cancer $[14,17,18]$.

Inflammation is normally related to oxidative stress in chronic disease, in which there is an increase of free radicals, such as superoxide, hydroxyl and peroxyl radicals. The imbalance of these chemical species may trigger atherosclerosis, cataract and inflammation [19]. Phenolic compounds and flavonoids have shown antioxidant activity, through several mechanisms, such as free radical inhibition, peroxide decomposition or oxygen scavenging $[20,21]$. Traditional medicine uses fennel to treat a wide range of health disorders linked to the digestive, reproductive, respiratory and endocrine systems due to its many pharmacological activities [1].

Fennel's industrial processes create large quantities of by-products that may be rich in bioactive compounds. Thus, this work evaluates the possibility of recovering these wastes to use them in the formulation of nutraceuticals or cosmetics.

Metabolomics is a large-scale analytical approach and lends itself well to the identification of specialized metabolites of plant species [22,23]. In this work, extracts obtained from different parts of the plant $F$. vulgare were analyzed through a Metabolite Profiling approach by using liquid chromatography coupled with mass spectrometry equipped with an electrospray source and orbitrap analyzer (LC-ESI/LTQOrbitrap/MS), which allowed the identification of several metabolites mainly belonging to hydroxycinnamic acid derivatives, flavonoid glycosides, flavonoid aglycons, phenolic acids, iridoid derivatives and lignans. LTQ Orbitrap can perform experiments in high-resolution mass spectrometry (HRMS) measuring accurately the molecular weight of the compounds revealed. Liquid chromatography coupled with tandem mass spectrometry $\left(\mathrm{LC}-\mathrm{MS}^{\mathrm{n}}\right)$ was able to separate, fragment and then characterize most of the plant metabolites from a vegetable source [24]. LC-ESI-FT-MS is typically applied and coupled with multivariate statistics and pathway analysis to obtain the relevant information [22].

So, the resulting data were processed with a multivariate statistical analysis approach, using Principal Component Analysis (PCA) and Partial Least Squares Discriminant Analysis (PLS-DA), projection methods. This allowed the classification of different parts of the fennel in relation to the metabolites characterizing them as markers.

Finally, spectrophotometric experiments have shown the waste of $F$. vulgare to be a good resource for producing functional ingredients for cosmetics and nutraceuticals. In fact, the antioxidant properties of extracts were evaluated by DPPH and TEAC assays, giving promising results.

\section{Materials and Methods}

\subsection{Raw Materials}

By-products of Foeniculum vulgare were provided by Paolillo (Eboli, Salerno, Italy), a company specialized in the production and marketing of fennel. The waste was recovered from the processing of fennel of the variety Tiziano cultivated in the locality of Campomarino in Puglia and harvested in December 2019. Parts of the fennel supplied were the white leaves forming the bulb, the superficial leaves and both the large stems and the smaller stems. Based on this, the samples were divided into the following four groups: FVBU_Foeniculum vulgare Bulb, FVST—Foeniculum vulgare Stem, FVLS—Foeniculum vulgare Little Stem, FVLE—Foeniculum vulgare Leaf.

\subsection{Reagents and Solvents}

Ethanol and water used for the extractions as well as the acetonitrile and water used for sep-paks were purchased from VWR (Milan, Italy). Acetonitrile (ACN), formic acid, water and methanol of LC-MS grade were supplied by Merk (Merk KGaA, Darmstadt, Germany). ABTS (2,2'-azino-bis(3-ethylbenzothiazoline-6-sulfonic acid)), Trolox (6-hydroxy-2,5,7,8tetramethylchroman-2-carboxylic acid), DPPH (2,2-Diphenyl-1-picrylhydrazyl), $\mathrm{NaOH}$ (sodium hydroxide), $\mathrm{NaNO}_{2}$ (sodium nitrite), $\mathrm{AlCl}_{3}$ (aluminum chloride), $\mathrm{K}_{2} \mathrm{~S}_{2} \mathrm{O}_{8}$ (potas- 
sium persulfate), PBS (Phosphate Buffered Saline), rutin and quercetin were purchased from Sigma-Aldrich (Milan, Italy).

\subsection{Sample Preparation}

Once the different parts of the fennel were divided, they were stored at $-80{ }^{\circ} \mathrm{C}$ and then freeze-dried. The freeze-dried plant materials were extracted with two types of extraction: sonication with a solution of ethanol/water (80:20) and water decoction.

As regards the sonication of FVBU and FVST samples $1 \mathrm{~g}$ of dried drugs were extracted with $20 \mathrm{~mL}$ of ethanol/water (80:20) for $15 \mathrm{~min}$ in the ultrasonic bath. On the other hand, $40 \mathrm{~mL}$ for $1 \mathrm{~g}$ of the matrix was required to extract the FVLS and FVLE samples. The extraction was repeated three times, filtering the extracts with filter paper. Decoction was carried out following EP pharmacopeia guidelines using $5 \mathrm{~g}$ of each sample in $100 \mathrm{~mL}$ of water. Only for the decoctions, a further purification step was required by using C18 cartridges (Phenomenex, Aschaffenburg, Germany). The cartridges were activated with $15 \mathrm{~mL}$ of $100 \% \mathrm{CH}_{3} \mathrm{CN}$, then conditioned with $15 \mathrm{~mL}$ of $10 \% \mathrm{CH}_{3} \mathrm{CN}$. One gram of sample was loaded over the column. For elution, a gradient starting from $10 \% \mathrm{CH}_{3} \mathrm{CN} / \mathrm{H}_{2} \mathrm{O}$ followed by $30 \% \mathrm{CH}_{3} \mathrm{CN} / \mathrm{H}_{2} \mathrm{O}$ and ending with $100 \% \mathrm{CH}_{3} \mathrm{CN}$ has been applied. The extracts were dried using a stream of nitrogen and then, for the LC-MS analysis, a solution of water/methanol (50:50) with a final concentration of $1 \mathrm{mg} / \mathrm{mL}$ of the extract was prepared for each sample.

\subsection{LC-ESI/LTQOrbitrap/MS}

Analysis and identification of specialized metabolites occurring in decoctions and ethanolic extracts were carried out by developing a method using an HPLC coupled with a hybrid mass spectrometer, which combines the linear trap quadrupole (LTQ) and Orbitrap mass analyzer. The experiments were executed with a Thermo scientific liquid chromatography system, equipped with a quaternary Accela 600 pump and an Accela autosampler, combined with a Linear Trap-Orbitrap hybrid mass spectrometer (LTQ-Orbitrap $\mathrm{XL}$, Thermo Fisher Scientific, Bremen, Germany) equipped with an electrospray ionization (ESI) source. A Phenomenex Luna C18 $5 \mu \mathrm{m}(150 \times 2.00 \mathrm{~mm})$ column (Phenomenex Aschaffenburg, Germany) was used to perform the separation. The mobile phases employed were water $+0.1 \%$ formic acid (A) and acetonitrile $+0.1 \%$ formic acid (B). An increasing linear-gradient $(v / v)$ at a flow rate of $0.200 \mathrm{~mL} / \mathrm{min}$ of solvent $\mathrm{B}$ was used: $0-10 \mathrm{~min}$, from 5 to $15 \% ; 10-30 \mathrm{~min}$, from 15 to $35 \% ; 30-40$, from 35 to $80 \%$ and then back to $5 \%$ for $10 \mathrm{~min}$ [9]. The mass spectrometer operated in negative ion mode and $10 \mu \mathrm{L}$ of each sample was used for injection. ESI source parameters were the following: capillary voltage $-48 \mathrm{~V}$; tube lens voltage $-176.47 \mathrm{~V}$; ion source temperature $280^{\circ} \mathrm{C}$; sheath and auxiliary gas flow $\left(\mathrm{N}_{2}\right), 15$ and 5; sweep gas 0; capillary voltage $3.5 \mathrm{kV}$. The full range $\mathrm{m} / \mathrm{z}$ adapted to the acquisition of MS spectra was 180-1400. For the fragmentation study, a data-dependent scan was set up through which the precursor ions corresponding to the most intensive peaks were fragmented in the LC-MS analysis with a collision energy of $30 \%$. Xcalibur software version 2.2 was used for instrument control, data acquisition and data analysis.

\subsection{Multivariate Data Analysis}

To better classify the samples and evaluate the different expressions of specialized metabolites in the four sample classes of F. vulgare (FVBU, FVST, FVLS, FVLE), both the LC-ESI/LTQ-Orbitrap/MS chromatograms of the ethanolic extracts and those of the decoctions were subjected to chemometric analyses such as Principal Component Analysis (PCA) and Partial Least Square Discriminant Analysis (PLS-DA). Each chromatogram was processed using open-source software for mass-spectrometry data processing called MZmine (http:/ / mzmine.sourceforge.net/) accessed on 20 July 2020. This software allowed compensating retention time and removing noise from LC-MS profiles setting the noise level to $1.0 \times 10^{4}$, so the data points below this value were not considered in the multivariate analysis. The dataset was exported and processed by SIMCAP+ software 12.0 (Umetrix AB, 
Umea Sweden) for the PCA, a projection method that allows samples to be grouped based on similarity in the composition of metabolites. The data were scaled to Unit Variance before multivariate data analysis. After PCA, PLS-DA was also carried out to identify the different metabolites between the various groups of the samples [25]. In this analysis, numeric values were assigned to the four classes of samples (FVBU, -2 ; FVST, -1 ; FVLS, +1; FVLE, +2) to use the regression algorithm necessary to classify the information on the different types of samples.

\subsection{DPPH• Radical Scavenging Activity}

The antiradical activity of the various parts of $F$. vulgare was evaluated using the stables 1,1-diphenyl-2-picrylhydrazyl radical (DPPH•) and the procedure previously described [26].

A methanolic solution of DPPH• with a concentration of $0.025 \mathrm{~g} / \mathrm{L}$ was prepared. An aliquot $(37.5 \mu \mathrm{L})$ of the methanolic solution containing different amounts of each extract $(0.625-1.25-2.5$ and $5 \mathrm{mg} / \mathrm{mL})$ was added to $1.5 \mathrm{~mL}$ of DPPH• solution previously prepared. The control tubes were prepared by adding equal volume $(37.5 \mu \mathrm{L})$ of the vehicle alone in $1.5 \mathrm{~mL}$ of DPPH• solution. The incubation time of the reaction was $10 \mathrm{~min}$. After this time, the absorbance at $517 \mathrm{~nm}$ was measured on a UV-visible spectrophotometer (Spectrophotometer Multiskan Go, Thermo Scientific). All experiments were carried out in triplicate.

The extracts with antioxidant activity reduce the radical DPPH• in the compound $\mathrm{DPPH}-\mathrm{H}$, causing a reduction in absorbance. So, the antiradical activity of the extracts was assessed as a decrease of the absorbance at $517 \mathrm{~nm}$, more precisely expressed as the percentage of the radical inhibition of DPPH according to Equation (1):

$$
\% \text { Inhibition DPPH } \bullet=\frac{A_{0}-A_{\mathrm{e}}}{A_{0}} \times 100
$$

$A_{0}$ is the average of the absorbances of the control in triplicate and $A_{\mathrm{e}}$ is the average of the absorbances of each concentration of the various extracts in triplicate.

\subsection{Trolox Equivalent Antioxidant Capacity (TEAC) Assay}

The antioxidant capacity of the extracts was determined by the Trolox Equivalent Antioxidant Capacity (TEAC) assay as previously reported [27]. The extracts were diluted with methanol/water producing solutions with the following concentrations: 250, 500, 750, $1000 \mu \mathrm{g} / \mathrm{mL}$. The assay was set up in the 96-well plates, combining $15 \mu \mathrm{L}$ of each sample with $150 \mu \mathrm{L}$ of ABTS. The absorbance was measured at $734 \mathrm{~nm}$. All experiments were carried out in triplicate.

The percent decrease of absorbance was determined for each concentration relative to a blank absorbance (methanol/water) and was plotted as a function of the concentration of compound or standard, 6-hydroxy-2,5,7,8-tetramethylchroman-2-carboxylic acid (Trolox).

The antioxidant activities are expressed as a TEAC value, that is, the concentration of a standard Trolox solution with the same antioxidant capacity as $1 \mathrm{mg} / \mathrm{mL}$ of the tested extract; quercetin 3-O-glucoside was used as a reference compound.

\subsection{Total Flavonoid Assay}

The total flavonoid content was measured using the Allumine Chloride colorimetric assay using rutin as a standard following the procedure previously described with slight modification [28]. Then, $1 \mathrm{~mL}$ of each sample with a concentration of $1 \mathrm{mg} / \mathrm{mL}$ and $4 \mathrm{~mL}$ of water was added in a 10-milliliter volumetric flask. After this, $0.3 \mathrm{~mL}$ of $5 \% \mathrm{NaNO}_{2}$ was added to the flask and then, $5 \mathrm{~min} 0.3 \mathrm{~mL}$ of $10 \% \mathrm{AlCl}_{3}$ was also added. After $6 \mathrm{~min}, 2 \mathrm{~mL}$ $1 \mathrm{M} \mathrm{NaOH}$ was added and the end-water was added to the solution to reach the volume of $10 \mathrm{~mL}$. The solutions were mixed well, and the absorbance was measured against the blank control at $510 \mathrm{~nm}$ on a UV-visible spectrophotometer. 
The content of flavonoids in the various extracts was expressed in rutin equivalents (RE) according to Equation (2):

$$
\text { Flavonoid amount }=\frac{A * m_{0} * 10}{A_{0} * m}
$$

Flavonoid amount was expressed in $\mathrm{mg} / \mathrm{g}$ plant extracts in RE; in the equation, $A$ is the average of the absorbance of extract in triplicate, $A_{0}$ is the average of the absorbance of standard rutin solution in triplicate, $m$ is the weight of the plant extract analyzed in $\mathrm{g}$ and $m_{0}$ is the weight of the rutin in the solution in $\mathrm{g}$.

\section{Results}

\subsection{Identification of Metabolites in F. vulgare Extracts by LC-ESI/LTQOrbitrap/MS and LC-ESI-LTQOrbitrap/MS/MS Analysis}

Metabolite profiles of hydroalcholic and decoction extracts obtained from waste of F. vulgare, were analyzed by LC-ESI-LTQ-MS/MS and investigated by Xcalibur Software (Figures 1 and 2). The accurate mass measurement $(\mathrm{ppm} \leq 5)$ and fragmentation experiments (MS/MS), associated with research in specific databases on spectral data for natural substances as KNApSAcK (www.knapsackfamily.com) accessed on 20 July 2020 and in the literature for the species $F$. vulgare allowed the putative identification of secondary metabolites mainly belonging to flavonoid glycosides (22-25,28-29), phenolic glycosides $(4,51)$, coumarins (11 and 19), phenolic acids (1-5-6-10-16-17-27-31-32), iridoid derivates (2-7-12-13-18), lignans (14-43-44-50), oxylipins (35-36-54) and lipids (9, 39, 40 and 41) (Tables 1 and 2).
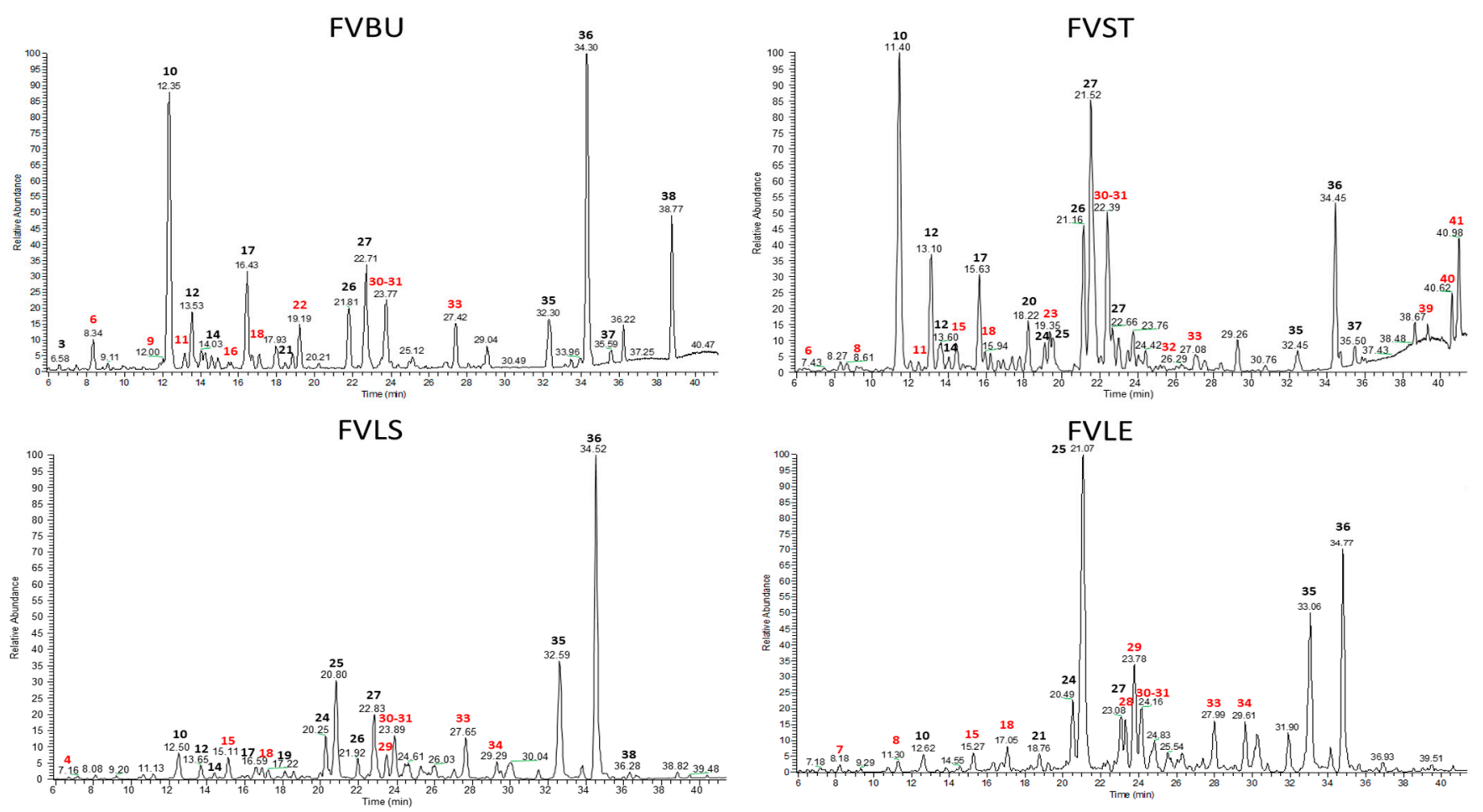

Figure 1. Negative ion mode profiles of F. vulgare waste ethanolic extracts obtained by LC-ESI/LTQ/Orbitrap MS: FVBU (Foeniculum vulgare Bulb), FVST (Foeniculum vulgare Stem), FVLE (Foeniculum vulgare Leaf) and FVLS (Foeniculum vulgare Little Stem). The compounds marked in red were identified only in the ethanolic extracts and not in the decoctions. 
FVBU
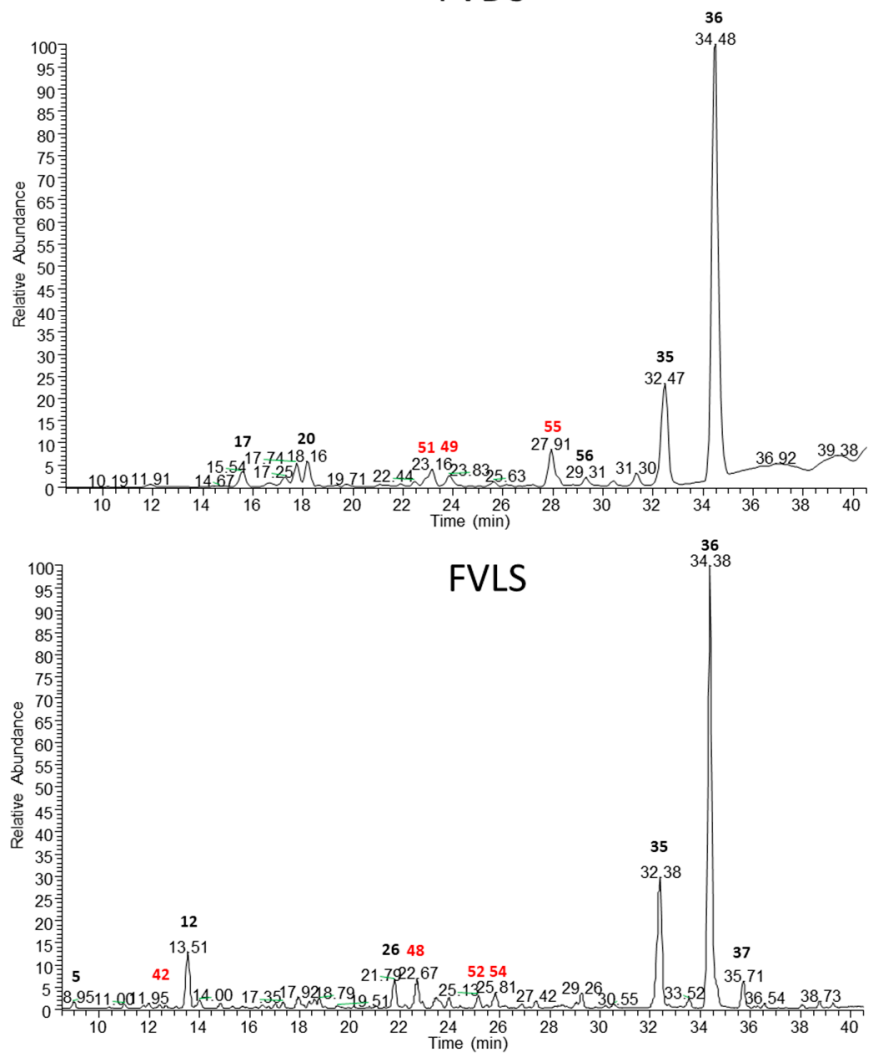

FVST
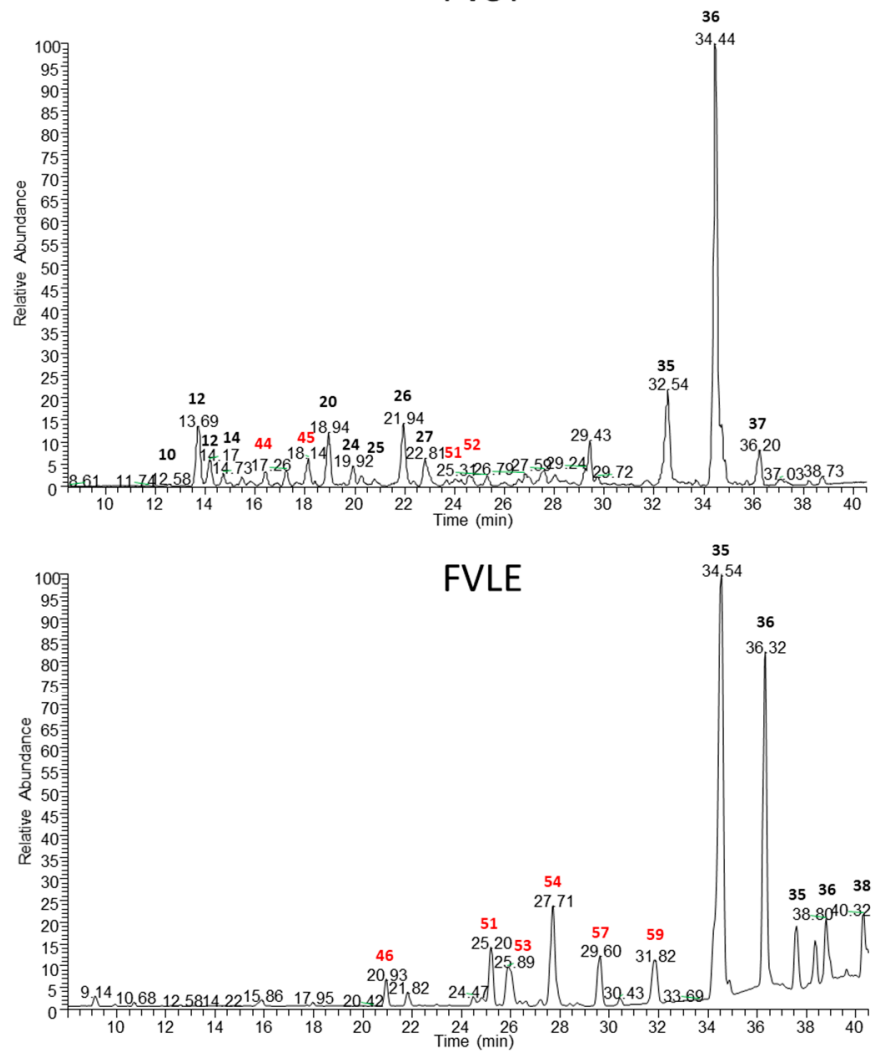

Figure 2. Negative ion mode profiles of F. vulgare waste decoctions obtained by LCESI/LTQ/Orbitrap MS: FVBU (Foeniculum vulgare Bulb), FVST (Foeniculum vulgare Stem), FVLE (Foeniculum vulgare Leaf) and FVLS (Foeniculum vulgare Little Stem). The compounds marked in red were identified only in the decoctions and not in the ethanolic extracts.

Among the metabolites previously identified in F. vulgare, flavonoid glycosides were found in fennel waste like flavonoid-O-rhamnoglucoside (22), for which the presence of the rhamnoglucoside unit was ascertained by checking neutral loss at 308 a.m.u.

Also, compounds 23 e 24 showed a fragmentation pattern corresponding to flavonoid glycosides. These compounds showed, in the LC-ESI/LTQOrbitrap/MS spectrum, product ions at $m / z 285$ and 301 peculiars of kaempferol and quercetin, respectively, originated by a sugar loss.

Other flavonoid glycosides, already present in the fennel literature, found in the waste of $F$. vulgare are flavonoid-O-glucuronides such as quercetin-O-glucuronide (25), luteolin$O$-glucuronide (28), isorhamnetin-O-glucuronide (29), which were identified by a neutral loss scan of 176 a.m.u. corresponding to the uronic acid unit.

Peaks of $m / z 353.0872,367.1026,337.0920$ revealed the presence of chlorogenic acid (10), feruloyl quinic acid derivate (17) and coumaroylquinic acid (16), whereas a peak of $\mathrm{m} / z 515.1182$ showed dicaffeoylquinic acid (27), phenolic acids previously identified in F. vulgare [9].

Other metabolites identified for the first time in fennel, previously reported in the Umbelliferae family, were the polyphenolic compound 4 (myrciaphenone A), the phenolic acid 5 (4-glucopyranosyloxy-3-methoxy benzeneacetic acid), the coumarin derivate 11 (fraxin) and the two lignans 14 (glehlinoside $\mathrm{C}$ ) and 44 (secoisolariciresinol $O$-hesoside). 


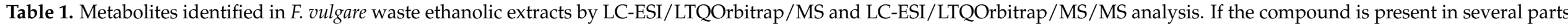
of the fennel, the RT is referred to as the profiles of FVBU, except for the compounds with * which are referred to as the profiles of FVLE.

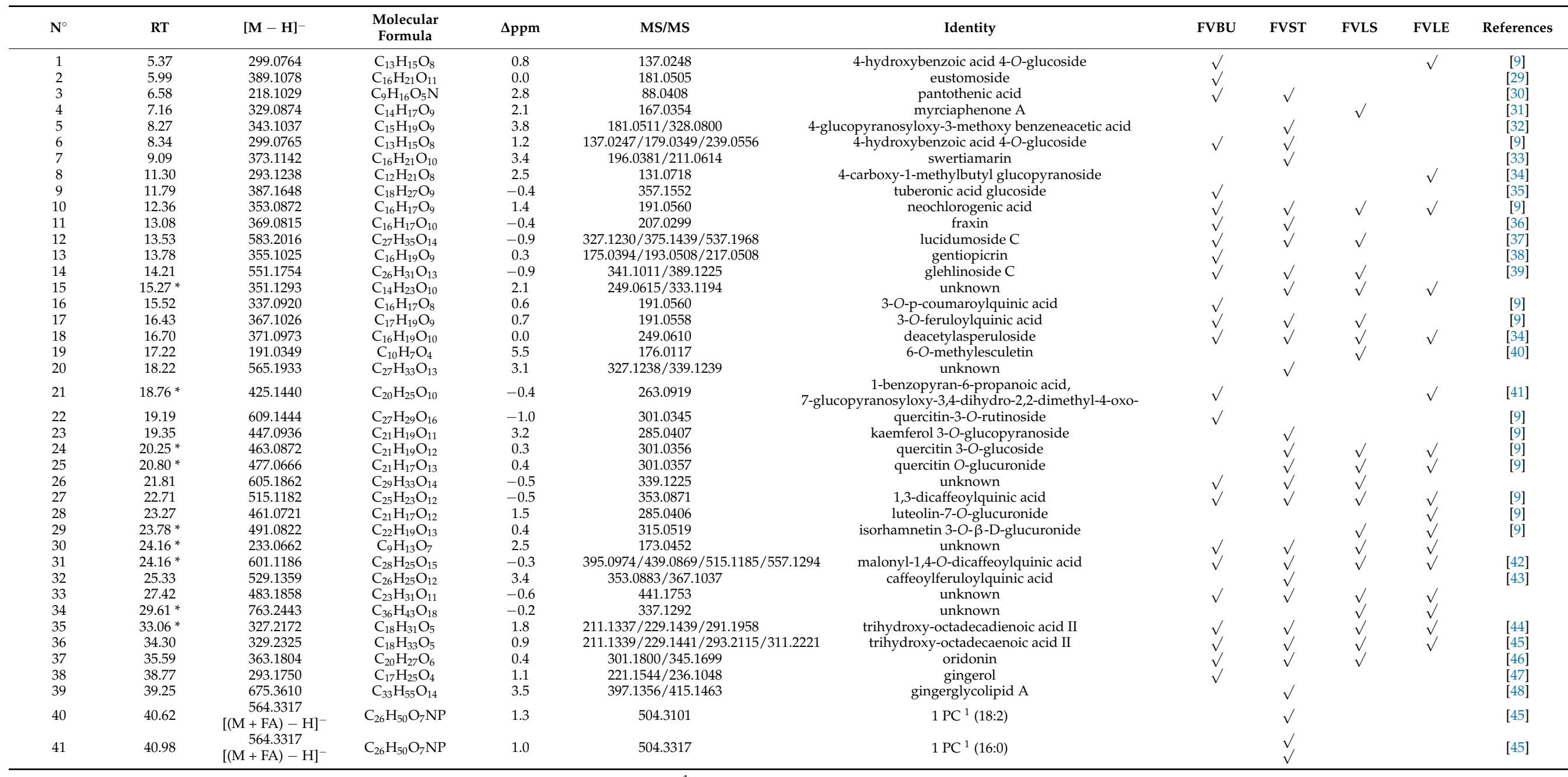

${ }^{1}$ PC = PhosphatidylCholine. 
Other metabolites identified in this work for the first time both in F. vulgare and in the Umbelliferae family were the compounds 2, 7, 12 and 18, which were identified as iridoids derivates.

Compounds 35, 36 and 54 were identified as oxylipins, in particular, the fragmentation pattern of the compounds 35 and 36 was characterized by the fragmentation of the bond in the vicinity of the hydroxyl group, producing fragment ions at $m / z 211$, a similar fragmentation was reported in Abelmoschus esculentus fruit [49], thus the compounds were identified as trihydroxy-octadecadienoic acid II, and they were for the first time reported in F. vulgare.

Compounds 38 and 51 were putatively identified as gingerol and lusitanicoside, respectively; lusitanicoside was characterized on the basis of the presence of the fragment ion at $m / z$ 133.06, due to the neutral loss of rutinoside moiety [46,50].

Compound 39 was proposed as gingerglycolipid A, which is the glycosylmonoacylglycerol of organic compounds, its fragment ion at $m / z 675.3610$ is like the fragmentation patterns already reported in the literature [48].

Compounds 40 and 41 were identified as phospholipids in the ethanolic extracts of the steam of F. vulgare. They were characterized by a phospholipid structure in which there is glycerol, with one fatty acylated and the nitrogenated head group corresponding to choline [45].

Peaks at $m / z 375.1444$ and 519.1858 showed the presence of two lignans, cycloolivil (43) and pinoresinol-4-O-glucoside (50). They were identified only in decoctions of F. vulgare.

\subsection{Multivariate Data Analysis}

The chromatograms obtained by LC-ESI/LTQ-Orbitrap/MS of the ethanolic extracts and of the decoctions were subjected to chemometric analysis, and specifically to Principal Component Analysis (PCA) and Partial Least Squares-Discriminant Analysis (PLS-DA), for better understanding of the data and for evaluating the different expressions of the metabolites of the four parts of F. vulgare (FVBU, FVST, FVLS and FVLE).

The raw data were pre-processed with MZmine (http://mzmine.sourceforge.net/) accessed on 20 July 2020, producing two data matrices, one for the ethanolic extracts and another for decoctions with rows representing the individual samples analyzed (36 samples each data matrix: 12 biological samples in technical triplicates) and columns representing integrated and normalized peak areas (108 variables for ethanolic extracts, 120 variables for decoctions).

After PCA, PLS-DA was applied; the validation of the model was obtained using a permutation test. Classification of the samples was carried out for both types of extracts, obtaining two different plots colored according to the parts of the plant under investigation (Figures 3 and 4).

The PLS-DA model representative obtained for the data acquired for ethanolic extracts showed the first component explaining $38 \%$ of the variance and the third explaining the $5 \%$ of the variance with a Q2 of 79\%. The PLS-DA model representative of the decoctions showed the first component explaining $20 \%$ of the variance and the third explaining the $4 \%$ of the variance with a Q2 of $54 \%$.

The score plot of the PLS-DA of the ethanolic extracts (Figure 3A) showed similarity in metabolic expression in the bulb and in the steam (FVBU and FVST) of F. vulgare, in fact, they are grouped in the lower right part of the plot. Instead, the leaf and the little steam (FVLE and FVLS) form two distinct and separate clusters in the left part of the plot.

The loading plot (Figure 3B) allowed the identification of the metabolites responsible for differentiating the samples. Increased expression of chlorogenic acid (10) and glucoside quercetin (24) was found in the leaf, while a greater expression of some quinic acid derivatives as feruloyl quinic acid (17) and coumaroyl quinic acid (16) was found in the bulb. Other metabolites expressed in the ethanolic extracts of the four parts of fennel are represented in Figure 3B. 


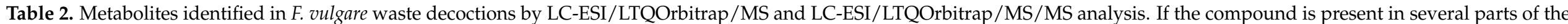
fennel, the RT is referred to as the profiles of FVST, except for the compounds with * which are referred to as the profiles of FVLE.

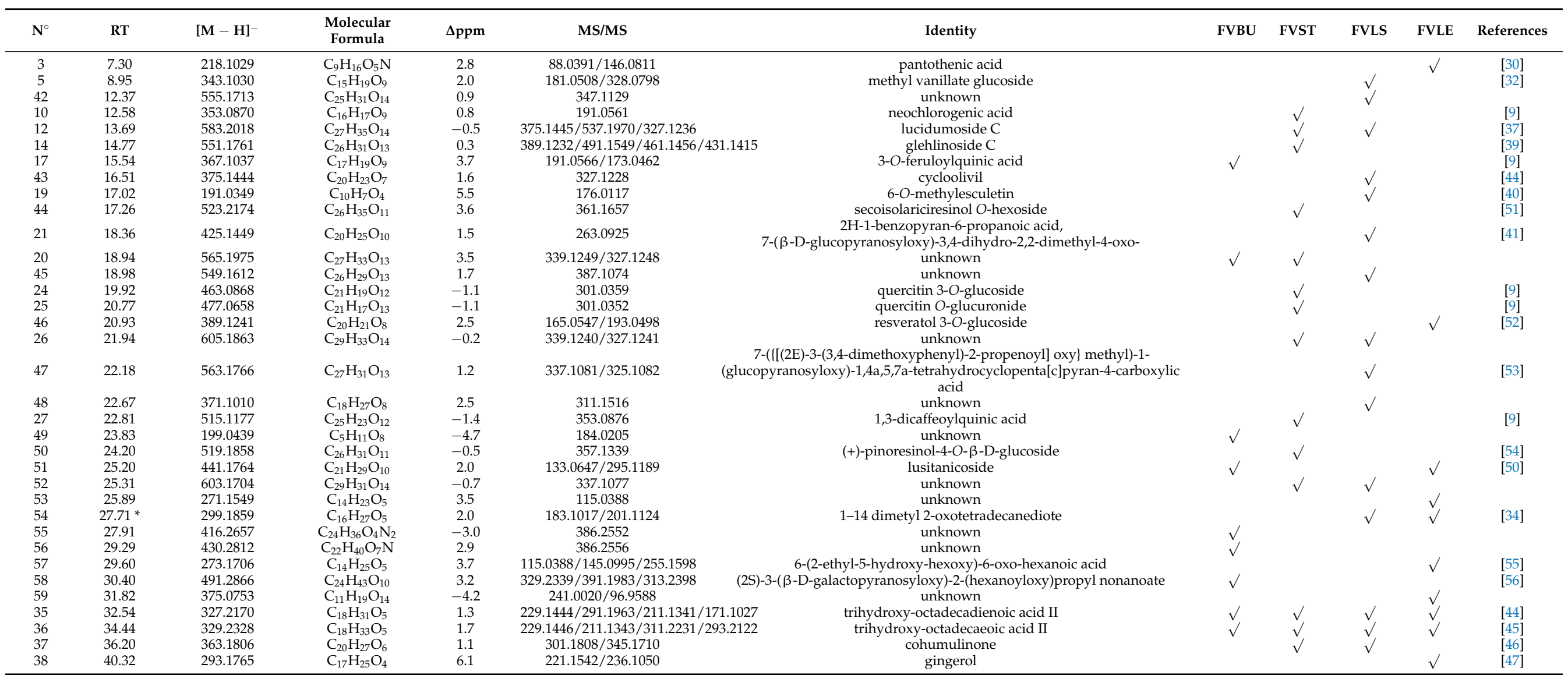



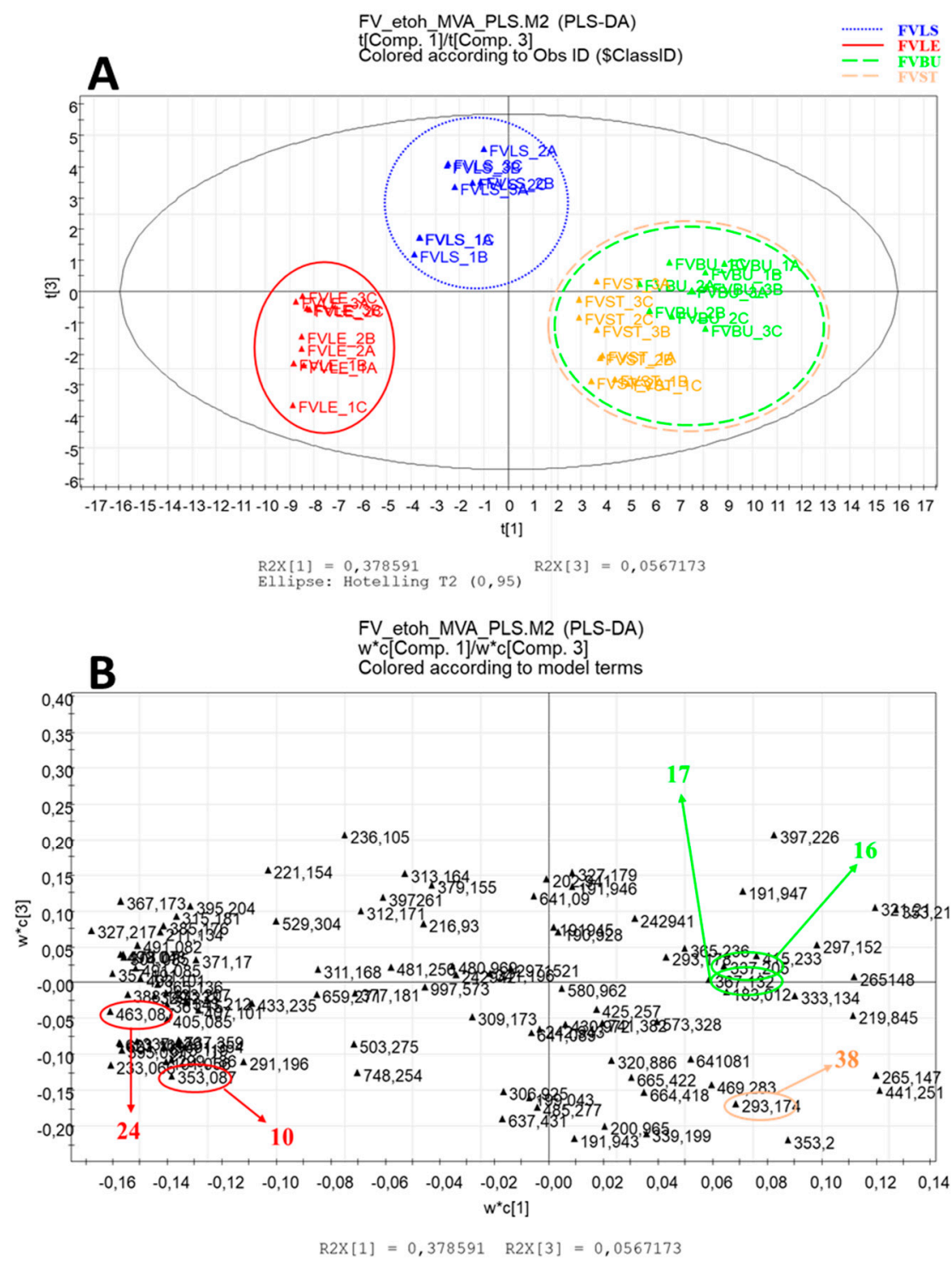

Figure 3. Partial Least Squares Discriminant Analysis (PLS-DA) of ethanolic extracts of F. vulgare. (A) score scatter plot; (B) loading plot with identifications of biomarkers.

The PLS-DA obtained for data acquired for decoctions (Figure 4A) revealed a different clustering of the samples: the bulb and stem are graphically well-differentiated from the rest of the samples, while the leaf and the little stem are more like each other and are placed in the lower left part of the plot.

The loading plot (Figure 4B) showed that dicaffeoyl quinic acid (27) is one of the most expressed metabolites in the bulb, responsible for the sample separation from the other parts of F. vulgare. The leaf is rich in lusitanicoside (51) and oxylipin trihydroxy-octadecadienoic acid II (35), while the steam is high in other oxylipin trihydroxy-octadecaeoic acid II content (36). Other metabolites expressed in the decocts of the four parts of the fennel are represented in Figure 4B. 

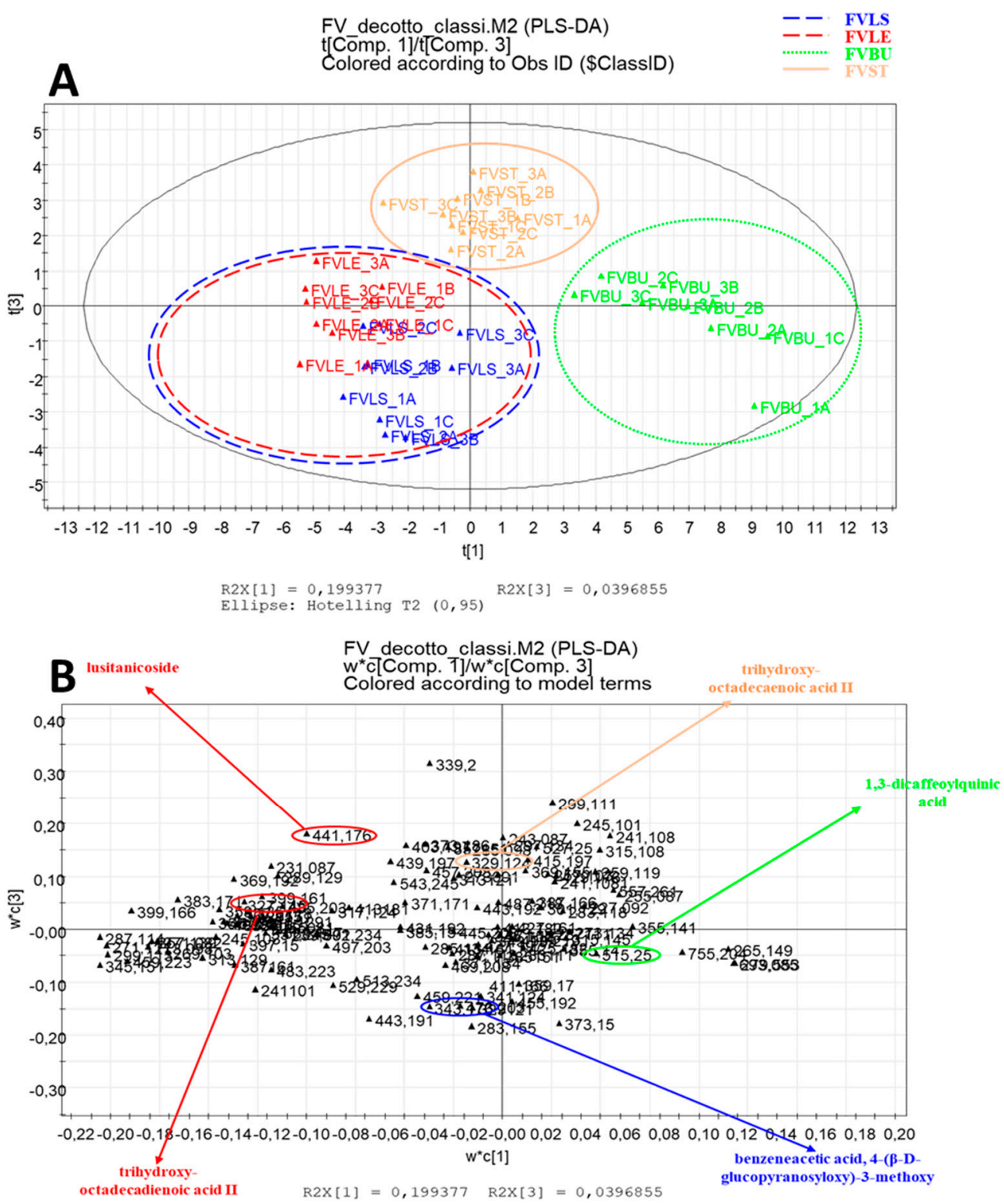

Figure 4. Partial Least Squares Discriminant Analysis (PLS-DA) of decoctions of F. vulgare. (A) score scatter plot; (B) loading plot with identifications of biomarkers.

\subsection{Antioxidant Activity and Content of Flavonoid}

As a preliminary step, the antioxidant activity of the various extracts was evaluated through spectrophotometric chemical assays in which the reducing power of the samples against the radical DPPH was measured.

The fennel extract that showed a greater antioxidant property was one obtained from the leaf, that reached, at a concentration of $5 \mathrm{mg} / \mathrm{mL}$, a percentage of DPPH inhibition at about $80 \%$ for decoction and about $90 \%$ for ethanol extract. While the one from the stem at the highest concentration was active in both types of extracts (50\% hydroalcoholic extracts, $60 \%$ decoctions), the bulb and smaller stem showed a good percentage of inhibition only for ethanol extracts (75\% FVBU and 63\% FVLS) (Figure 5).

The antioxidant activity of the various parts of the fennel was also evaluated with the TEAC assay. The higher TEAC values (Table 3 ) of the extracts of $F$. vulgare were shown by both types of extracts of the leaf of fennel, according to the DPPH assay. 


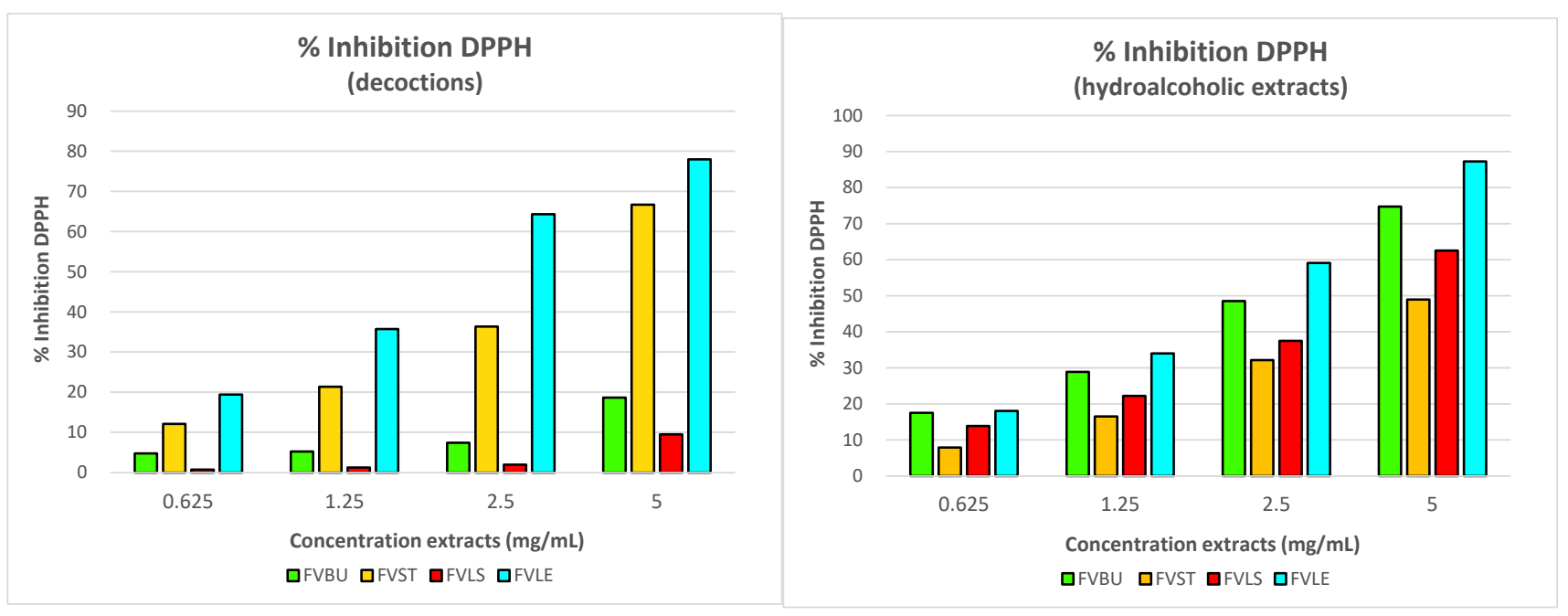

Figure 5. Percentage of inhibition of the radical DPPH of F. vulgare. The concentrations of the tested extracts are $0.625,1.25$, 2.5 and $5 \mathrm{mg} / \mathrm{mL}$. The percent of inhibition of DPPH is the average of three experiments and the standard deviation values range from 0.01 to 0.05 .

Table 3. Antioxidant activity of extracts of F. vulgare evaluated by Trolox Equivalent Antioxidant Capacity (TEAC).

\begin{tabular}{|c|c|}
\hline $\begin{array}{l}\text { F. vulgare } \\
\text { Extracts }\end{array}$ & $\begin{array}{c}\text { TEAC } \\
{\left[\mathrm{mg} / \mathrm{mL} \pm \mathrm{SD}^{\mathrm{a}}\right]^{\mathrm{b}}}\end{array}$ \\
\hline $\begin{array}{c}\text { FVBU } \\
\text { Hydroalcoholic }\end{array}$ & $0.334 \pm 0.007$ \\
\hline $\begin{array}{c}\text { FVBU } \\
\text { Decoctions }\end{array}$ & $0.393 \pm 0.003$ \\
\hline $\begin{array}{c}\text { FVST } \\
\text { Hydroalcoholic }\end{array}$ & $0.347 \pm 0.004$ \\
\hline $\begin{array}{c}\text { FVST } \\
\text { Decoctions }\end{array}$ & $0.426 \pm 0.014$ \\
\hline $\begin{array}{c}\text { FVLS } \\
\text { Hydroalcoholic }\end{array}$ & $0.375 \pm 0.006$ \\
\hline $\begin{array}{c}\text { FVLS } \\
\text { Decoctions }\end{array}$ & $0.407 \pm 0.011$ \\
\hline $\begin{array}{c}\text { FVLE } \\
\text { Hydroalcoholic }\end{array}$ & $0.823 \pm 0.008$ \\
\hline $\begin{array}{c}\text { FVLE } \\
\text { decoctions }\end{array}$ & $0.570 \pm 0.009$ \\
\hline
\end{tabular}

a SD: Standard Deviation of three independent experiments; ${ }^{\text {b }}$ Determined by TEAC assay.

In addition, according to the important biological activities of flavonoids, their amount was assessed by a spectrophotometric assay, in which the flavonoids produce a yellow complex with $\mathrm{Al}^{3+}$, which can be revealed at a wavelength of $510 \mathrm{~nm}$. The major quantity of flavonoids, expressed in rutin equivalents (RE), was found in the leaf of F. vulgare, with $0.206 \mathrm{mg} / \mathrm{g}$ plant extract (hydroalcoholic) and $0.263 \mathrm{mg} / \mathrm{g}$ plant extract (decoction) (Table 4).

The antioxidant activity shown by the different parts of $F$. vulgare could be due to the metabolites characterized through the LC-ESI-FT-MS analysis, in fact, there is evidence in the literature in which the antioxidant activity of quinic acid derivatives [57] and flavonoids [58] has been studied. 
Table 4. Total amount of plant flavonoids in F. vulgare extracts.

\begin{tabular}{cc}
\hline $\begin{array}{c}\text { F. vulgare } \\
\text { Extracts }\end{array}$ & $\begin{array}{c}\text { Total Flavonoids } \\
{\left[\mathbf{m g} / \mathbf{g} \text { Plant Extract (in RE) } \pm \mathbf{S D}^{\mathbf{a}}\right]^{\mathbf{b}}}\end{array}$ \\
\hline $\begin{array}{c}\text { FVLE } \\
\text { hydroalcoholic } \\
\text { FVLE } \\
\text { decoctions }\end{array}$ & $0.206 \pm 0.006$ \\
\hline
\end{tabular}

a SD: Standard Deviation of three independent experiments; ${ }^{\mathrm{b}}$ Determined by Allumine Chloride assay.

\section{Conclusions and Discussion}

The present study allowed the characterization of metabolites present in different parts of $F$. vulgare waste. The use of two different types of extraction, ultrasonically assisted hydroalcoholic extraction and decoction, showed that a higher detection of metabolites is obtained through ethanol extraction (41 metabolites) compared to decoction (38 metabolites).

Among the metabolites identified exclusively in hydroalcoholic extracts, there are: iridoids (2, 7, 13 and 18), phenylpropanoids (16 and 31), glycoside flavonoids (22, 23, 28 and 29), the glycolipid 39 and the two phospholipids 40 and 41 . Furthermore, the three metabolites belonging to the class of lignans $(43,44$ and 50) were identified only in the decoctions of fennel, along with the flavonoid resveratrol glucoside (46) and the oxylipin 54 .

By comparing the metabolites identified in the different parts of $F$. vulgare waste, it can be observed that rutin (22) is present only in the bulb (FVBU). The representative peak of gingerol (38) in the LC-MS profile, also present in the small stems (FVLS), turns out to have greater intensity in the bulb. As for the metabolite profile of the stem (FVST), it is the only part of the fennel waste in which lipids 39,40 and 41 were found. The flavonoids 24 and 25 , present in all samples except in the FVBU, show greater intensity in the metabolite profile of the leaf (FVLE).

The interesting data that emerged from this metabolic analysis concern the presence, in each part of the F. vulgare waste, of the oxylipins 35 and 36, metabolites identified for the first time in fennel. The potential antitumor role of this class of metabolites has been reported in the literature [11]. In addition, there is evidence that many plant species belonging to the family Apiaceae, known for their potential cytotoxic, anti-inflammatory and anticancer properties, have been reported to contain metabolites belonging to this class of compounds, suggesting that such biological properties may be due not only to phenolic compounds but also to oxylipins [59].

Chemometric analyses enabled a better interpretation of the metabolic analysis data and made clearer the different metabolic expressions of the four classes of samples analyzed (FVBU, FVST, FVLS and FVLE). Although Principal Component Analysis and Partial Least Square Analysis of the samples obtained through hydroalcoholic extraction were not identical to those obtained for decoctions, it is evident from both score plots that the bulb and stem show more similar metabolic expression than the leaf and the small stem.

Both the assay to evaluate the content of flavonoids and those to evaluate the antioxidant activity of the different parts of fennel suggest that the leaf is the most active part. Based on those data, the loading plots of multivariate statistical analysis propose which metabolites are most expressed in FVLE samples $(10,24,35,51)$, and which could be the cause of the best biological activities of the $F$. vulgare leaf, making it the best source of bioactive compounds and therefore the most promising part to be valorized with the aim to produce functional or nutraceutical products.

The metabolomics approach here described allowed the characterization of the parts of fennel not used in the food industry and destined to become vegetable waste. These parts of $F$. vulgare are rich in bioactive compounds potentially useful for producing functional and nutraceutical products. It would be interesting to isolate these metabolites to evaluate the biological activities of individual compounds, with the aim to produce functional products enriched with bioactive compounds. 
Author Contributions: Conceptualization, P.M. and M.A.C.; methodology, P.M., G.D. and M.A.C.; software, P.M., G.D. and M.A.C.; validation, P.M., G.D. and M.A.C.; formal analysis, P.M., G.D. and M.A.C.; investigation, P.M., G.D. and M.A.C.; resources, P.M. and S.P.; data curation, P.M., G.D. and M.A.C.; writing—original draft preparation, M.A.C.; writing—review and editing, P.M. and G.D.; visualization, P.M. and S.P.; supervision, P.M. and S.P.; project administration, P.M.; funding acquisition, P.M. and S.P. All authors have read and agreed to the published version of the manuscript.

Funding: This research received no external funding.

Institutional Review Board Statement: Not applicable.

Informed Consent Statement: Not applicable.

Data Availability Statement: Not applicable.

Conflicts of Interest: The authors declare no conflict of interest.

\section{References}

1. Badgujar, S.B.; Patel, V.V.; Bandivdekar, A.H. Foeniculum vulgare Mill: A review of its botany, phytochemistry, pharmacology, contemporary application, and toxicology. Biomed. Res. Int. 2014, 2014, 842674. [CrossRef] [PubMed]

2. Rahimi, R.; Ardekani, M.R. Medicinal properties of Foeniculum vulgare Mill. in traditional Iranian medicine and modern phytotherapy. Chin. J. Integr. Med. 2013, 19, 73-79. [CrossRef] [PubMed]

3. Anka, Z.M.; Gimba, S.; Nanda, A.; Lawan, S. Phytochemistry and pharmacological activities of Foeniculum vulgare. IOSR J. Pharm. 2020, 10, 1-10.

4. Coman, V.; Teleky, B.E.; Mitrea, L.; Martău, G.A.; Szabo, K.; Călinoiu, L.F.; Vodnar, D.C. Bioactive potential of fruit and vegetable wastes. Adv. Food Nutr. Res. 2020, 91, 157-225. [CrossRef]

5. Sagar, N.A.; Pareek, S.; Sharma, S.; Yahia, E.M.; Lobo, M.G. Fruit and vegetable waste: Bioactive compounds, their extraction, and possible utilization. Compr. Rev. Food Sci. Food Saf. 2018, 17, 512-531. [CrossRef]

6. Saravanan, K.; Aradhya, S.M. Potential nutraceutical food beverage with antioxidant properties from banana plant bio-waste (pseudostem and rhizome). Food Funct. 2011, 2, 603-610. [CrossRef]

7. Lopez-Sanchez, P.; de Vos, R.C.; Jonker, H.H.; Mumm, R.; Hall, R.D.; Bialek, L.; Leenman, R.; Strassburg, K.; Vreeken, R.; Hankemeier, T.; et al. Comprehensive metabolomics to evaluate the impact of industrial processing on the phytochemical composition of vegetable purees. Food Chem. 2015, 168, 348-355. [CrossRef]

8. Chiboub, W.; Sassi, A.B.; Amina, C.M.; Souilem, F.; El Ayeb, A.; Djlassi, B.; Ascrizzi, R.; Flamini, G.; Harzallah-Skhiri, F. Valorization of the green waste from two varieties of fennel and carrot cultivated in Tunisia by identification of the phytochemical profile and evaluation of the antimicrobial activities of their essentials oils. Chem. Biodivers. 2019, 16, e1800546. [CrossRef]

9. Parejo, I.; Jauregui, O.; Sánchez-Rabaneda, F.; Viladomat, F.; Bastida, J.; Codina, C. Separation and characterization of phenolic compounds in fennel (Foeniculum vulgare) using liquid chromatography-negative electrospray ionization tandem mass spectrometry. J. Agric. Food Chem. 2004, 52, 3679-3687. [CrossRef]

10. Cautela, D.; Vella, F.M.; Castaldo, D.; Laratta, B. Characterization of essential oil recovered from fennel horticultural wastes. Nat. Prod. Res. 2019, 33, 1964-1968. [CrossRef]

11. Christensen, L.P.; Brandt, K. Bioactive polyacetylenes in food plants of the Apiaceae family: Occurrence, bioactivity and analysis. J. Pharm. Biomed. Anal. 2006, 41, 683-693. [CrossRef] [PubMed]

12. Imran, A.; Xiao, L.; Ahmad, W.; Anwar, H.; Rasul, A.; Imran, M.; Aziz, N.; Razzaq, A.; Arshad, M.U.; Shabbir, A.; et al. Foeniculum vulgare (Fennel) promotes functional recovery and ameliorates oxidative stress following a lesion to the sciatic nerve in mouse model. J. Food Biochem. 2019, 43, e12983. [CrossRef]

13. Rosa, J.S.; Oliveira, L.; Sousa, R.M.O.F.; Escobar, C.B.; Fernandes-Ferreira, M. Bioactivity of some Apiaceae essential oils and their constituents against. Bull. Entomol. Res. 2020, 110, 406-416. [CrossRef] [PubMed]

14. Jaw-Ming, C.; Wen, C.; Lien-Chai, C. Immunomodulatory activities of common vegetables and spices of Umbelliferae and its related coumarins and flavonoids. Food Chem. 2008, 106, 944-950.

15. Cicero, A.F.G.; Fogacci, F.; Colletti, A. Food and plant bioactives for reducing cardiometabolic disease risk: An evidence based approach. Food Funct. 2017, 8, 2076-2088. [CrossRef]

16. Olivares-Vicente, M.; Barrajon-Catalan, E.; Herranz-Lopez, M.; Segura-Carretero, A.; Joven, J.; Encinar, J.A.; Micol, V. Plantderived polyphenols in human health: Biological activity, metabolites and putative molecular targets. Curr. Drug Metab. 2018, 19, 351-369. [CrossRef] [PubMed]

17. De Oliveira, R.G.; Mahon, C.P.; Ascêncio, P.G.; Ascêncio, S.D.; Balogun, S.O.; de Oliveira Martins, D.T. Evaluation of antiinflammatory activity of hydroethanolic extract of Dilodendron bipinnatum Radlk. J. Ethnopharmacol. 2014, 155, 387-395. [CrossRef] [PubMed]

18. Mahbub, A.A.; Le Maitre, C.L.; Haywood-Small, S.L.; McDougall, G.J.; Cross, N.A.; Jordan-Mahy, N. Differential effects of polyphenols on proliferation and apoptosis in human myeloid and lymphoid leukemia cell lines. Anticancer Agents Med. Chem. 2013, 13, 1601-1613. [CrossRef] 
19. Biswas, S.K. Does the interdependence between oxidative stress and inflammation explain the antioxidant paradox? Oxid. Med. Cell. Longev. 2016, 2016, 5698931. [CrossRef]

20. Faudale, M.; Viladomat, F.; Bastida, J.; Poli, F.; Codina, C. Antioxidant activity and phenolic composition of wild, edible, and medicinal fennel from different Mediterranean countries. J. Agric. Food Chem. 2008, 56, 1912-1920. [CrossRef]

21. Hussain, T.; Tan, B.; Yin, Y.; Blachier, F.; Tossou, M.C.; Rahu, N. Oxidative stress and inflammation: What polyphenols can do for us? Oxid. Med. Cell. Longev. 2016, 2016, 7432797. [CrossRef] [PubMed]

22. Jacobs, D.M.; Van Den Berg, M.A.; Hall, R.D. Towards superior plant-based foods using metabolomics. Curr. Opin. Biotechnol. 2021, 70, 23-28. [CrossRef]

23. Astarita, G.; Langridge, J. An emerging role for metabolomics in nutrition science. J Nutr. Nutr. 2013, 6, 181-200. [CrossRef]

24. D'Urso, G.; Pizza, C.; Piacente, S.; Montoro, P. Combination of LC-MS based metabolomics and antioxidant activity for evaluation of bioactive compounds in Fragaria vesca leaves from Italy. J. Pharm. Biomed. Anal. 2018, 150, 233-240. [CrossRef]

25. Brennan, L. Metabolomics in nutrition research: Current status and perspectives. Biochem Soc. Trans. 2013, 41, 670-673. [CrossRef]

26. Cerulli, A.; Lauro, G.; Masullo, M.; Cantone, V.; Olas, B.; Kontek, B.; Nazzaro, F.; Bifulco, G.; Piacente, S. Cyclic diarylheptanoids from Corylus avellana green leafy covers: Determination of their absolute configurations and evaluation of their antioxidant and antimicrobial activities. J. Nat. Prod. 2017, 80, 1703-1713. [CrossRef] [PubMed]

27. Kılınç, H.; Masullo, M.; D’Urso, G.; Karayildirim, T.; Alankus, O.; Piacente, S. Phytochemical investigation of Scabiosa sicula guided by a preliminary HPLC-ESIMS. Phytochemistry 2020, 174, 112350. [CrossRef] [PubMed]

28. Dobravalskyte, D.; Venskutonis, P.R.; Talou, T. Antioxidant properties and essential oil composition of Calamintha grandiflora L. Food Chem. 2012, 135, 1539-1546. [CrossRef]

29. Olennikov, D.N.; Gadimli, A.I.; Isaev, J.I.; Kashchenko, N.I.; Prokopyev, A.S.; Kataeva, T.N.; Chirikova, N.K.; Vennos, C. Caucasian Gentiana Species: Untargeted LC-MS metabolic profiling, antioxidant and digestive enzyme inhibiting activity of six plants. Metabolites 2019, 9, 271. [CrossRef] [PubMed]

30. La Guardia, M.; Venturella, G.; Venturella, F. On the chemical composition and nutritional value of Pleurotus taxa growing on umbelliferous plants (apiaceae). J. Agric. Food Chem. 2005, 53, 5997-6002. [CrossRef]

31. Gurbuz, P.; Baran, M.Y.; Demirezer, L.O.; Guvenalp, Z.; Kuruuzum-Uz, A. Phenylacylated-flavonoids from Peucedanum chryseum. Rev. Bras. Farmacogn. 2018, 28, 228-230. [CrossRef]

32. Hisamoto, M.; Kikuzaki, H.; Nakatani, N. Constituents of the leaves of Peucedanum japonicum Thunb. and their biological activity. J. Agric. Food Chem. 2004, 52, 445-450. [CrossRef]

33. Pan, Y.; Zhang, J.; Shen, T.; Zhao, Y.L.; Wang, Y.Z.; Li, W.Y. Comparative metabolic fingerprinting of Gentiana rhodantha from different geographical origins using LC-UV-MS/MS and multivariate statistical analysis. BMC Biochem. 2015, 16, 9. [CrossRef]

34. Rodríguez-Pérez, C.; Gómez-Caravaca, A.M.; Guerra-Hernández, E.; Cerretani, L.; García-Villanova, B.; Verardo, V. Comprehensive metabolite profiling of Solanum tuberosum L. (potato) leaves by HPLC-ESI-QTOF-MS. Food Res. Int. 2018, 112, 390-399. [CrossRef] [PubMed]

35. Taamalli, A.; Arráez-Román, D.; Abaza, L.; Iswaldi, I.; Fernández-Gutiérrez, A.; Zarrouk, M.; Segura-Carretero, A. LC-MS-based metabolite profiling of methanolic extracts from the medicinal and aromatic species Mentha pulegium and Origanum majorana. Phytochem. Anal. 2015, 26, 320-330. [CrossRef] [PubMed]

36. Wang, H.; Xiao, B.; Hao, Z.; Sun, Z. Simultaneous determination of fraxin and its metabolite, fraxetin, in rat plasma by liquid chromatography-tandem mass spectrometry and its application in a pharmacokinetic study. J. Chromatogr. B Anal. Technol. Biomed. Life Sci. 2016, 1017-1018, 70-74. [CrossRef]

37. Quirantes-Piné, R.; Lozano-Sánchez, J.; Herrero, M.; Ibáñez, E.; Segura-Carretero, A.; Fernández-Gutiérrez, A. HPLC-ESI-QTOFMS as a powerful analytical tool for characterising phenolic compounds in olive-leaf extracts. Phytochem. Anal. 2013, 24, 213-223. [CrossRef] [PubMed]

38. Silveira, E.S.; Bezerra, S.B.; Ávila, K.S.; Rocha, T.M.; Pinheiro, R.G.; de Queiroz, M.G.R.; Magalhães, P.J.C.; Santos, F.A.; Leal,

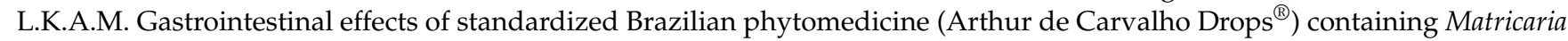
recutita, Gentiana lutea and Foeniculum vulgare. Pathophysiology 2019, 26, 349-359. [CrossRef]

39. Wang, C.; Zhang, N.; Wang, Z.; Qi, Z.; Zheng, B.; Li, P.; Liu, J. Rapid characterization of chemical constituents of Platycodon grandiflorum and its adulterant Adenophora stricta by UPLC-QTOF-MS/MS. J. Mass Spectrom. 2017, 52, 643-656. [CrossRef]

40. Abdel-Fattah, M.E.; Taha, K.E.; Aziz, M.H.; Missalem, A.A.; El-Khrisy, E.A.M. Chemical constituents of Citrus limonia and Foeniculum vulgare. Indian J. Heterocycl. Chem. 2003, 13, 45-48.

41. Kitajima, J.; Ishikawa, T.; Tanaka, Y.; Ida, Y. Constituents of fennel. X. New chromanone and phenylethanoid glycosides, and threo-epoxyanethole. Chem. Pharm. Bull. 1999, 47, 1448-1450. [CrossRef]

42. Valente, I.M.; Moreira, M.M.; Neves, P.; da Fé, T.; Gonçalves, L.M.; Almeida, P.J.; Rodrigues, J.A. An insight on salting-out assisted liquid-liquid extraction for phytoanalysis. Phytochem. Anal. 2017, 28, 297-304. [CrossRef] [PubMed]

43. Miles, C.A.; Collins, T.S.; Mu, Y.; Alexander, T.R. Identifying bulb fennel cultivars suitable for production in the Northwest United States. HortTechnology 2019, 29, 496-506. [CrossRef]

44. Zhang, J.; Zhang, F.; Li, D.; Liu, Y.; Liu, B.; Meng, X. Characterization of metabolite profiles of white and green spears of Asparagus officinalis L. from Caoxian, East China. Food Res. Int. 2020, 128, 108869. [CrossRef] [PubMed]

45. Napolitano, A.; Cerulli, A.; Pizza, C.; Piacente, S. Multi-class polar lipid profiling in fresh and roasted hazelnut (Corylus avellana cultivar "Tonda di Giffoni") by LC-ESI/LTQOrbitrap/MS/MS. Food Chem. 2018, 269, 125-135. [CrossRef] 
46. Liu, P.; Du, Y.; Zhang, X.; Sheng, X.; Shi, X.; Zhao, C.; Zhu, H.; Wang, N.; Wang, Q.; Zhang, L. Rapid Analysis of 27 components of Isodon serra by LC-ESI-MS-MS. Chromatographia 2010, 72, 265-273. [CrossRef]

47. Peixoto Araujo, N.M.; Arruda, H.S.; Dos Santos, F.N.; de Morais, D.R.; Pereira, G.A.; Pastore, G.M. LC-MS/MS screening and identification of bioactive compounds in leaves, pulp and seed from Eugenia calycina Cambess. Food Res. Int. 2020, 137, 109556. [CrossRef]

48. Ismail, B.B.; Pu, Y.; Guo, M.; Ma, X.; Liu, D. LC-MS/QTOF identification of phytochemicals and the effects of solvents on phenolic constituents and antioxidant activity of baobab (Adansonia digitata) fruit pulp. Food Chem. 2019, 277, 279-288. [CrossRef] [PubMed]

49. D'Urso, G.; Napolitano, A.; Cannavacciuolo, C.; Masullo, M.; Piacente, S. Okra fruit: LC-ESI/LTQOrbitrap/MS/MS. Food Funct. 2020, 11, 7856-7865. [CrossRef]

50. Lazarova, I.; Zengin, G.; Gevrenova, R.; Nedialkov, P.; Aneva, I.; Aumeeruddy, M.Z.; Mahomoodally, M.F. A comparative study of UHPLC/Orbitrap MS metabolomics profiles and biological properties of Asphodeline taurica from Bulgaria and Turkey. J. Pharm. Biomed. Anal. 2019, 168, 174-180. [CrossRef] [PubMed]

51. Yuan, Z.; Tezuka, Y.; Fan, W.; Kadota, S.; Li, X. Constituents of the underground parts of Glehnia littoralis. Chem. Pharm. Bull. 2002, 50, 73-77. [CrossRef]

52. De Marino, S.; Gala, F.; Borbone, N.; Zollo, F.; Vitalini, S.; Visioli, F.; Iorizzi, M. Phenolic glycosides from Foeniculum vulgare fruit and evaluation of antioxidative activity. Phytochemistry 2007, 68, 1805-1812. [CrossRef]

53. Jia, J.; Liu, M.; Wen, Q.; He, M.; Ouyang, H.; Chen, L.; Li, J.; Feng, Y.; Zhong, G.; Yang, S. Screening of anti-complement active ingredients from Eucommia ulmoides Oliv. branches and their metabolism in vivo based on UHPLC-Q-TOF/MS/MS. J. Chromatogr. B Anal. Technol. Biomed. Life Sci. 2019, 1124, 26-36. [CrossRef]

54. Wei, L.; Mei, Y.; Zou, L.; Chen, J.; Tan, M.; Wang, C.; Cai, Z.; Lin, L.; Chai, C.; Yin, S.; et al. Distribution patterns for bioactive constituents in pericarp, stalk and seed of Forsythiae fructus. Molecules 2020, 25, 340. [CrossRef] [PubMed]

55. Made Ratih, G.A.; Imawati, M.F.; Nugroho, R.R.; Purwanti, D.I.; Wongso, S.; Prajogo, B.; Indrayanto, G. Phytochemicals of Gandarusa (Justicia gendarussa) and Its Preparations. Nat. Prod. Commun. 2019, 14, 1934578X19851406. [CrossRef]

56. Nadeem, M.; Mumtaz, M.W.; Danish, M.; Rashid, U.; Mukhtar, H.; Irfan, A.; Anwar, F.; Saari, N. UHPLC-QTOF-MS/MS metabolites profiling and antioxidant/antidiabetic attributes of Cuscuta reflexa grown on Casearia tomentosa: Exploring phytochemicals role via molecular docking. Int. J. Food Prop. 2020, 23, 918-940. [CrossRef]

57. El-Askary, H.I.; Mohamed, S.S.; El-Gohari, H.M.A.; Ezzat, S.M.; Meselhy, M.R. Quinic acid derivatives from Artemisia annua L. leaves; biological activities and seasonal variation. S. Afr. J. Bot. 2020, 128, 200-208. [CrossRef]

58. Chu, C.; Du, Y.; Yu, X.; Shi, J.; Yuan, X.; Liu, X.; Liu, Y.; Zhang, H.; Zhang, Z.; Yan, N. Dynamics of antioxidant activities, metabolites, phenolic acids, flavonoids, and phenolic biosynthetic genes in germinating Chinese wild rice (Zizania latifolia). Food Chem. 2020, 318, 126483. [CrossRef] [PubMed]

59. Christensen, L.P. Bioactive C 17 and C 18 acetylenic oxylipins from terrestrial plants as potential lead compounds for anticancer drug development. Molecules 2020, 25, 2568. [CrossRef] 